ISSN : 2549-2314;

Volume : 1 ; Number 1

\title{
PENGARUH KOMPOSISI LARUTAN CETAK DAN TEMPERATUR PENGADUKAN TERHADAP KARAKTERISTIK FISIK, MEKANIK DAN PERMEABILITAS AIR MURNI MEMBRAN Polyether imide
}

\author{
Nita Kusumawati ${ }^{\star}$, Pirim Setiarso, Maria Monica Sianita \\ Jurusan Kimia, Universitas Negeri Surabaya, Ketintang, Surabaya, 60231, Indonesia \\ * Corresponding author, email: nitakusumawati@unesa.ac.id \\ Co-author 1, email: pirimsetiarso@unesa.ac.id \\ Co-author 2, email: mariamonicasianita@unesa.ac.id
}

\begin{abstract}
In this research, optimization of polyetherimide membrane (PEI) has been made using induced phase inversion method of immersion-precipitation process. To obtain a membrane with surface morphology, mechanical characteristics and pure water permeability, optimization for a composition of the casting solution and the stirring temperature has been performed. The optimization was carried out in the range of casting solution $\mathrm{PEI} / \mathrm{NMP} / \mathrm{NH}_{4} \mathrm{Cl}$ with composition (\% $\left.w / w\right) 8 / 84 / 8-14 / 84 / 2$ and the stirring temperature of $60-100^{\circ} \mathrm{C}$. In addition, a whole of $\mathrm{PEI}$ membrane made with gauze support solid. The result of surface morphology analysis using Scanning Electron Microscopy (SEM) showed the decrease of pore size on PEI membrane skin layer along with an increase in the composition of the casting solution and the stirring temperature.Young modulus values of the prepared PEI membrane are in the range 1,124 - 1,676 N/m2 for casting solution composition 8/84/8 - 14/84/2 (\% $b / b)$ and 1,443-1,898 N/m2 for stirring temperature $60-100{ }^{\circ} \mathrm{C}$. The result of pure water permeability analysis using "Dead end" membrane reactor showed membrane flux value at 56.611 101.553 L / m2.hours for casting solution composition 14/84/2 - 8/84/8 (\% b / b) and 48,547 - 67,245 L / m2.hours for stirring temperature $100-60^{\circ} \mathrm{C}$. Thus, it can be said that increasing the PEI composition in the casting solution and the stirring temperature has resulted in increased mechanical strength and decreased the permeability of pure water.
\end{abstract}

Keywords: Membrane; phase inversion; immersion;precipitation; polyetherimide

\section{ABSTRAK}

Pada penelitian ini telah dilakukan optimasi pembuatan membran polyether imide (PEI) menggunakan metode inversi fasa terinduksi proses imersi-presipitasi. Untuk mendapatkan membran dengan morfologi permukaan, karakteristik mekanik dan permeabilitas air murni, telah dilakukan optimasi komposisi larutan cetak dan temperatur pengadukan. Optimasi dilakukan pada rentang komposisi larutan cetak PEI/NMP/NH ${ }_{4} \mathrm{Cl}(\% \mathrm{~b} / \mathrm{b})$ 8/84/8 - 14/84/2 dan temperatur pengadukan 60 $100^{\circ} \mathrm{C}$. Sebagai tambahan, seluruh pembuatan membran PEI dilakukan dengan menggunakan padatan pendukung kain kasa. Hasil analisis morfologi permukaan menggunakan Scanning Electron Microscopy (SEM) menunjukkan terjadinya penurunan ukuran pori pada lapisan kulit membran PEI seiring dengan peningkatan komposisi larutan cetak dan temperatur pengadukan. Nilai modulus Young membran PEI yang dipreparasi berada pada rentang $1.124-1.676 \mathrm{~N} / \mathrm{m}^{2}$ untuk komposisi larutan cetak 8/84/8 - 14/84/2 (\%b/b) dan $1.443-1.898 \mathrm{~N} / \mathrm{m}^{2}$ untuk temperatur pengadukan $60-100$ ${ }^{\circ} \mathrm{C}$. Hasil analisis permeabilitas air murni menggunakan reaktor membran "Dead end" menunjukkan nilai fluks membran pada 56.611 - $101.553 \mathrm{~L} / \mathrm{m}^{2}$.jam untuk komposisi larutan cetak 14/84/2 - 8/84/8 (\%b/b) dan 48.547-67.245 L/m².jam untuk temperatur pengadukan $100-60 \stackrel{\circ}{\circ}$. Dengan demikian, dapat dikatakan bahwa, peningkatan komposisi PEI dalam larutan cetak dan temperatur pengadukan telah menghasilkan peningkatan kekuatan mekanik dan penurunan permeabilitas air murni.

Kata Kunci: Membran; inversi fasa; imersi; presipitasi; polyether imide 


\section{PENDAHULUAN}

Saat ini, teknologi membran merupakan bagian yang tak terpisahkan dari proses industri. Penggunaan membran dalam industri telah meluas di berbagai bidang, antara lain industri logam, industri makanan dan biokimia, industri kertas dan pulp, di bidang kesehatan, industri tekstil, industri proses kimia, dan pengolahan limbah [1].

Berbagai material dapat digunakan untuk membuat membran. Material tersebut dapat berupa bahan organik atau anorganik. Pembuatan membran dari material dengan teknik dan kondisi tertentu, dapat menghasilkan membran yang spesifik terhadap suatu proses pemisahan [2]. Selain itu, material membran yang digunakan, akan membatasi teknik pembuatan yang digunakan dan morfologi membran yang diperoleh [3]. Oleh karena itu, menjadi penting untuk mengetahui pengaruh komposisi larutan cetak dan temperatur pengadukan sebagai bagian dari parameter teknik pembuatan terhadap karakteristik fisik, mekanik, dan permeabilitas air murni material polyether imide (PEI) sebagai salah satu polimer unggulan dalam dunia membran.

Polyetherimide (PEI) merupakan polimer amorf dengan $\mathrm{Tg}$ di sekitar $200{ }^{\circ} \mathrm{C}$. Material ini dapat digunakan pada temperatur tinggi dan material ini juga dikenal karena kekuatannya. Selain itu, PEI juga memiliki ketahanan termal dan kimiawi yang baik sehingga menjadikannya sebagai salah satu kandidat potensial bagi sejumlah aplikasi kontaktor [4]-[6]. Karakteristik dan kinerja yang baik dari membrane PEI disebabkan oleh hubungan eter yang fleksibel pada polymer backbone [7]. PEI telah digunakan secara ekstensif dalam fabrikasi membran asimetri, baik pada skala ultrafiltrasi [8] maupun nanofiltrasi [9].

Selama ini, membran PEI telah berhasil dipreparasi dengan menggunakan 2 macam metode, yaitu sintering dan track etching [10]. Namun saat ini, sintesis membran PEI dengan metode inversi fasa mulai banyak diteliti, terutama karena prosesnya yang lebih sederhana dan skala produksinya yang fleksibel. Dengan demikian, biaya produksi yang relatif rendah dapat tetap dipertahankan [2]. Selain itu, membran asimetri umumnya dipreparasi menggunakan inversi fasa dan secara lebih khusus menggunakan proses imersi presipitasi.

Inversi fasa dapat dideskripsikan sebagai proses demixing dimana larutan polimer homogen awal ditransformasikan dari wujud cair ke wujud padat dalam kondisi yang terkontrol [11]. Transformasi ini dapat dicapai melalui sejumlah teknik, yaitu (a) pemisahan fasa terinduksi termal (TIPS); (b) penguapan terkontrol pelarut dari sistem; (c) presipitasi dari fasa uap dan (d) imersi-presipitasi (IP) [3].

Pada proses inversi fasa terinduksi imersi presipitasi, larutan cetak yang mengandung polimer dilarutkan ke dalam pelarut yang sesuai, dicetak pada permukaan datar dan kemudian direndam dalam bak koagulasi yang berisi non pelarut. Pada kondisi ini, membrane dibentuk atau dipresipitasikan oleh pertukaran pelarut dan non pelarut melalui mekanisme difusi. Karakteristik membran yang difabrikasi dengan metode ini dipengaruhi oleh kondisi cetak polimer; terutama konsentrasi larutan cetak dan kondisi koagulasi. Pengaruh parameter inversi 
fasa telah dipelajari sebelumnya untuk banyak polimer termasuk membrane berbasis polyvinylidene fluoride (PVDF) [8]-[12], polysulfone (PSf) [8], [13], dan PEEK [8], [14].

Penelitian ini bertujuan untuk mengetahui pengaruh komposisi larutan cetak dan temperatur pengadukan terhadap morfologi permukaan, karakteristik mekanik dan permeabilitas air murni membran PEI. Oleh karena itu, pada penelitian ini dilakukan analisis intesnsif terhadap morfologi permukaan membran menggunakan Scanning Electron Microscopy (SEM), karakteristik mekanik menggunakan strograph, dan permeabilitas air murni menggunakan reaktor membran "Deadend".

\section{METODE}

\section{Material}

Material penelitian meliputi: Polyetherimide (PEI) (melt index 9 g/10 menit, $339^{\circ} \mathrm{C} / 6,6 \mathrm{~kg}$, Aldrich), ammonium chloride $\left(\mathrm{NH}_{4} \mathrm{Cl}\right)(\geq 99,5 \%$, Riedel De haen), N-Methyl-2pyrrolidone (NMP) $(\geq 99,7 \%$ Sigma Aldrich, BM = 99,13 g/mol), aquadestilata, dan kain kasa (Kasa Husada Indonesia, 254 mesh).

\section{Instrumentasi}

Peralatan penelitian meliputi: peralatan gelas (pyrex), neraca analitis Ohaus PAJ1003, NESCO LAB MS-H280-Pro hot plate magnetic stirrer untuk pengadukan material membran, casting knife dengan ketebalan cetak 0,8 mm, bak koagulasi (buatan sendiri) dengan volume $250 \mathrm{~mL}$, dan termometer. Sementara itu, instrument penelitian meliputi: reaktor membran dead end (buatan sendiri) yang dihubungkan dengan kompresor sebagai sumber tekanan (tekanan maksimum 6 bar), Nicolet IS10 Thermo
Fourier Transform Infra Red (FTIR), Zeiss EVO MA10 Scanning Electron Microscopy (SEM), RCT/10KN/AF TOYO SEIKI Strograph, Perkin Elmer STA-6000 Differential Scanning Calorymetry (DSC)-Thermal Gravimetric Analysis (TGA).

\section{Prosedur}

\section{Preparasi Membran PEI}

Membran PEI dengan komposisi larutan $\begin{array}{lllll}\text { cetak } & (\mathrm{PEI} / & \left.\mathrm{NMP} / \mathrm{NH}_{4} \mathrm{Cl}\right) & (\% \mathrm{~b} / \mathrm{b}) & 8 / 84 / 8\end{array}$ dipreparasi dengan metode inversi fasa. Untuk mendapatkan larutan homogen, $\mathrm{PEI}$ dan $\mathrm{NH}_{4} \mathrm{Cl}$ dilarutkan ke dalam pelarut NMP dan kemudian diaduk menggunakan magnetic stirrer selama 105 menit pada temperatur $60^{\circ} \mathrm{C}$. Larutan cetak homogen kemudian dicetak di atas padatan pendukung kain kasa dengan ketebalan cetak $0,8 \mathrm{~mm}$ dan selanjutnya didiamkan selama 5 menit. Pada tahapan berikutnya, larutan cetak direndam dalam bak koagulasi yang berisi non pelarut $\mathrm{H}_{2} \mathrm{O}$ dengan temperatur imersi $80^{\circ} \mathrm{C}$. Padatan membran PEI dicuci menggunakan aqua destilata untuk menghilangkan sisa-sisa pelarut dan porogen pada membran. Padatan membran dikeringkan di udara terbuka selama 24 jam. Untuk mengetahui pengaruh komposisi larutan cetak, pada penelitian ini komposisi larutan cetak divariasi pada $\left(\mathrm{PEI} / \mathrm{NMP} / \mathrm{NH}_{4} \mathrm{Cl}\right)$ (\%b/b) 8/84/8; 10/84/6; 12/84/4; dan 14/84/2. Sementara itu, untuk mengetahui pengaruh temperatur pengadukan, pada penelitian ini dilakukan variasi temperatur pengadukan pada $70 \stackrel{\circ}{ } \mathrm{C} ; 80 \stackrel{\circ}{ } \mathrm{C} ; 90 \stackrel{\circ}{ } \mathrm{C}$ dan $100 \stackrel{\circ}{ } \mathrm{C}$. 


\section{Karakterisasi Membran}

Karakterisasi membran PEI meliputi karakterisasi fisik dan mekanik. Pada penelitian ini, karakterisasi fisik menggunakan SEM dilakukan untuk mengetahui morfologi permukaan membran PEI. Sementara itu, karakterisasi mekanik menggunakan strograph dilakukan untuk menentukan kekuatan mekanik membran.

\section{Uji Permeabilitas Air Murni Membran}

Permeabilitas air murni membran PEI dievaluasi dengan mengukur fluks. Uji permeabilitas air murni dilakukan menggunakan membran dengan diameter $4,8 \mathrm{~cm}$ pada tekanan konstan 1 bar $\left(\mathrm{kg} / \mathrm{cm}^{3}\right)$ sebagai gaya dorong.

\section{Ketahanan Termal Membran}

Ketahanan termal membran PSf/PVDF dilakukan melalui evaluasi perubahan massa menggunakan TGA.

\section{HASIL DAN PEMBAHASAN}

\section{Karakteristik fisik membran PEI}

Pada gambar 1 tampak morfologi permukaan membran PEI dengan komposisi larutan cetak (PEI/NMP/NH $\left.{ }_{4} \mathrm{Cl}\right)(\% \mathrm{~b} / \mathrm{b})$ 8/84/8; 10/84/6; 12/84/4; dan 14/84/2. Morfologi permukaan membran menunjukkan bahwa peningkatan kadar PEI dalam larutan cetak telah menurunkan ukuran pori membran. Peningkatan kadar polimer PEI bersamaan dengan penurunan kadar porogen $\mathrm{NH}_{4} \mathrm{Cl}$ dalam larutan cetak telah mempersempit ruang antar molekul PEI dan berdampak pada penurunan ukuran pori membran, khususnya pada lapisan kulit membran yang bersangkutan.
Morfologi permukaan pada gambar 1 menunjukkan pori karakteristik membran PEI yang memiliki porositas tinggi dengan ukuran pori yang relatif kecil. Porositas tinggi pada membran PEI telah menjadi kompensasi untuk ukuran porinya yang kecil dalam rangka untuk mendapatkan permeabilitas yang tinggi. Di sisi lain, ukuran pori yang relatif kecil menyebabkan membran ini memiliki kekuatan mekanik dan selektivitas yang tinggi pada saat yang bersamaan. Kondisi inilah yang kemudian menyebabkan membran PEI memiliki karakteristik mekanik dan kinerja yang lebih baik dibandingkan dengan membran komersial lainnya, seperti PSf dan PVDF.

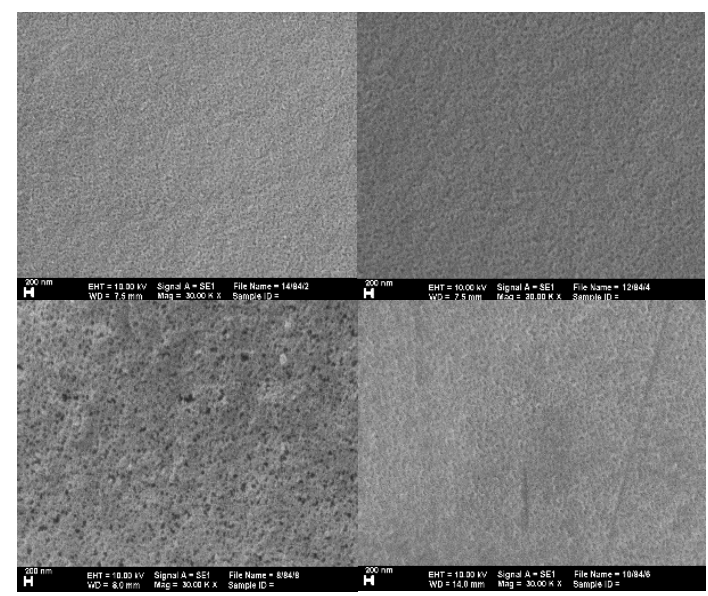

Gbr 1. morfologi permukaan membran PEI dengan komposisi larutan cetak (PEl/NMP/NH $4 \mathrm{Cl})(\% \mathrm{~b} / \mathrm{b})$ : (a) 14/84/2; (b) 12/84/4; (c) 10/84/6; dan (d) 8/84/8

Sejalan dengan pengaruh komposisi larutan cetak, peningkatan temperatur pengadukan juga telah menyebabkan terbentuknya membran PEI dengan ukuran pori yang lebih kecil. Peningkatan temperatur pengadukan telah menyediakan energi eksternal yang lebih besar bagi pelarutan senyawa $\mathrm{PEI}$ dan $\mathrm{NH}_{4} \mathrm{Cl}$ dalam $\mathrm{NMP}$ dan menciptakan larutan cetak yang lebih 
homogen. Pelarutan yang homogen akan menciptakan kondisi dimana aditif porogen $\mathrm{NH}_{4} \mathrm{Cl}$ akan terdistribusi secara lebih merata di ruang antar partikel polimer. Kondisi tersebut akan meningkatkan porositas dan menghambat terjadinya aglomerasi partikel yang berujung pada terciptanya macrovoid pada membran. Pada gambar 2 tampak morfologi permukaan membran PEI yang dipreparasi dengan variasi pada temperatur pengadukan.

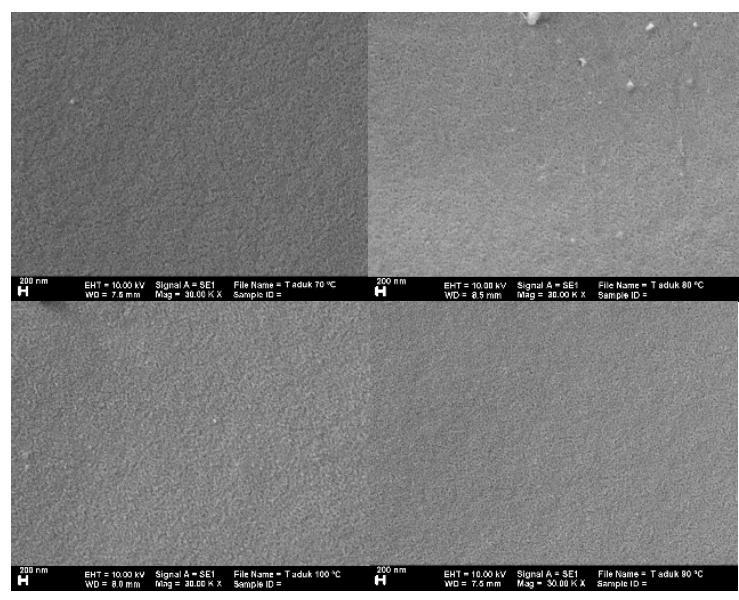

Gbr 2. morfologi permukaan membran PEI dengan temperatur pengadukan : (a) $70^{\circ} \mathrm{C}$; (b) $80^{\circ} \mathrm{C}$; (c) $90^{\circ} \mathrm{C}$; dan (d) $100 \stackrel{\circ}{C}$

\section{Karakteristik mekanik membran PEI}

Pada tabel 1 dan 2 tampak data kekuatan mekanik membran $\mathrm{PEI}$, yang masing-masing dipreparasi dengan variasi pada komposisi larutan cetak dan temperatur pengadukan. Berdasarkan hasil uji kekuatan mekanik, seperti yang tampak pada tabel 1 , tampak bahwa semakin meningkatnya kadar polimer PEI dalam larutan cetak, akan semakin meningkatkan kekuatan mekanik membran yang bersangkutan. Peningkatan kadar polimer PEI akan meningkatkan efek kesesakan ruang dalam larutan cetak membran. Peningkatan kadar polimer PEI dalam larutan cetak telah meningkatkan kerapatan interaksi antar molekul dan menyisakan lebih sedikit ruang kosong yang dikenal sebagai pori. Kondisi tersebut telah meningkatkan kemampuan membran dalam mempertahankan ukuran pori membran atau yang lebih dikenal sebagai modulus Young. Peningkatan kadar polimer PEI dalam larutan cetak dari $8 \%(b / b)$ menjadi $14 \%(b / b)$ telah mampu meningkatkan kekuatan mekanik membran PEI hingga sebesar $32,93 \%$.

Pada tabel 2, tampak bahwa peningkatan temperatur pengadukan larutan cetak membran telah meningkatkan kekuatan mekanik membran PEI. Minimumnya peristiwa aglomerasi, baik pada molekul PEI maupun $\mathrm{NH}_{4} \mathrm{Cl}$ sebagai dampak tingginya tingkat keteraturan dan homogenitas interaksi yang terbentuk di antara molekul polimer dan porogen dalam pelarut NMP telah menciptakan membran dengan porositas tinggi namun dengan ukuran pori yang cenderung kecil. Berdasarkan data pada tabel 2, tampak bahwa peningkatan temperatur pengadukan dari $60{ }^{\circ} \mathrm{C}$ menjadi $100{ }^{\circ} \mathrm{C}$ telah meningkatkan kekuatan mekanik membran hingga sebesar $31,48 \%$. Sementara itu, peningkatan temperatur pengadukan dari 60 ${ }^{\circ} \mathrm{C}$ hingga menjadi $70^{\circ} \mathrm{C}$; $80^{\circ} \mathrm{C}$; dan $90^{\circ} \mathrm{C}$, masing-masing telah meningkatkan kekuatan mekanik membran hingga sebesar 3,88\%; 9,47\%; dan 9,91\%. 
Tabel 1. Modulus Young Membran PEI (Variasi Komposisi Larutan Cetak)

\begin{tabular}{cccc}
\hline No & $\begin{array}{c}\text { Komposisi } \\
\text { Membran } \\
\left(\mathrm{PEI} / \mathrm{NMP} / \mathrm{NH}_{4} \mathrm{Cl}\right) \\
(\% \mathrm{~b} / \mathrm{b})\end{array}$ & $\begin{array}{c}\text { Temperatur } \\
\text { Pengadukan } \\
\left({ }^{\circ} \mathrm{C}\right)\end{array}$ & $\begin{array}{c}\text { Modulus } \\
\text { Young } \\
\left(\mathrm{N} / \mathrm{m}^{2}\right)\end{array}$ \\
\cline { 1 - 1 } & $8 / 84 / 8$ & & \\
\hline 1 & $10 / 84 / 6$ & 60 & 1,124 \\
\cline { 1 - 2 } & $12 / 84 / 4$ & & 1,347 \\
\hline 4 & $14 / 84 / 2$ & & 1,443 \\
\hline
\end{tabular}

Tabel 2. Modulus Young Membran PEI (Variasi Temperatur Pengadukan)

\begin{tabular}{|c|c|c|c|}
\hline No & $\begin{array}{c}\text { Komposisi } \\
\text { Membran } \\
\left(\mathrm{PEI} / \mathrm{NMP}^{\prime} / \mathrm{NH}_{4} \mathrm{Cl}\right) \\
(\% \mathrm{~b} / \mathrm{b})\end{array}$ & $\begin{array}{c}\text { Temperatur } \\
\text { Pengaduka } \\
n\left({ }^{\circ} \mathrm{C}\right)\end{array}$ & $\begin{array}{c}\text { Modulus } \\
\text { Young } \\
\left(\mathrm{N} / \mathrm{m}^{2}\right)\end{array}$ \\
\hline 1 & \multirow{5}{*}{$12 / 84 / 4$} & 60 & 1,443 \\
\hline 2 & & 70 & 1,499 \\
\hline 3 & & 80 & 1,580 \\
\hline 4 & & 90 & 1,586 \\
\hline 5 & & 100 & 1,898 \\
\hline
\end{tabular}

\section{Permeabilitas air murni membran PEI}

Pada tabel 3 dan 4 tampak data permeabilitas air murni membran $\mathrm{PEI}$, yang masing-masing dipreparasi dengan variasi pada komposisi larutan cetak dan temperatur pengadukan. Hasil uji permeabilitas membran PEI hasil variasi komposisi larutan cetak menggunakan reaktor membran "dead end" pada tekanan operasional 1 bar menunjukkan bahwa peningkatan kadar polimer PEI hingga sebesar $14 \%(b / b)$ dalam larutan cetak membran telah menurunkan permeabilitas membran terhadap larutan umpan air hingga sebesar 44,25\%. Sementara itu, peningkatan kadar polimer PEI hingga sebesar 13\%; 12\%; 11\%; 10\%; dan $9 \%$, telah menurunkan permeabilitas membran PEI masing-masing hingga sebesar 39,66\%; 33,78\%; 24,62\%; 22,22\%; dan $10,09 \%$.

Nilai permeabilitas air murni yang sangat tinggi, sebesar 101.553,36 L/m².jam dari membran PEI yang dipreparasi dari komposisi larutan cetak $\mathrm{PEI} / \mathrm{NMP} / \mathrm{NH}_{4} \mathrm{Cl}$ (\%b/b) 8/84/8 menjadi salah satu penanda dominasi macrovoid pada porous layer membran PEI. Kondisi ini akan berdampak langsung pada rendahnya selektivitas pemisahan yang dihasilkan oleh membran yang bersangkutan.

Tabel 3. Permeabilitas Air Murni Membran PEI (Variasi Komposisi Larutan Cetak)

\begin{tabular}{|c|c|c|c|}
\hline No & $\begin{array}{c}\text { Komposisi } \\
\text { Membran } \\
\left(\mathrm{PEI} / \mathrm{NMP} / \mathrm{NH}_{4} \mathrm{Cl}\right) \\
(\% \mathrm{~b} / \mathrm{b})\end{array}$ & $\begin{array}{l}\text { Temperatur } \\
\text { Pengadukan } \\
\left({ }^{\circ} \mathrm{C}\right)\end{array}$ & $\begin{array}{c}\text { Fluks } \\
\left(\mathrm{L} / \mathrm{m}^{2} \text {.jam }\right)\end{array}$ \\
\hline 1 & $8 / 84 / 8$ & \multirow{4}{*}{60} & 101.553 \\
\hline 2 & $10 / 84 / 6$ & & 78.986 \\
\hline 3 & $12 / 84 / 4$ & & 67.245 \\
\hline 4 & $14 / 84 / 2$ & & 56.611 \\
\hline
\end{tabular}

Sejalan dengan hasil uji permeabilitas air murni dari membrane PEI yang dipreparasi dengan variasi pada komposisi larutan cetak, hasil uji permeabilitas membran PEI hasil variasi temperatur pengadukan menunjukkan penurunan permeabilitas membran PEI yang terjadi seiring dengan peningkatan temperatur pengadukan larutan cetak. Peningkatan temperatur pengadukan larutan cetak membran dari $60{ }^{\circ} \mathrm{C}$ menjadi $100{ }^{\circ} \mathrm{C}$ telah menurunkan permeabilitas membran hingga sebesar $27,80 \%$. Sementara itu, peningkatan temperatur pengadukan dari $60^{\circ} \mathrm{C}$ hingga menjadi $70{ }^{\circ} \mathrm{C}$; $80{ }^{\circ} \mathrm{C}$; dan $90{ }^{\circ} \mathrm{C}$, masing-masing telah menurunkan permeabilitas membran PEI hingga sebesar $1,33 \% ; 6,33 \% ; 17,78 \%$; dan $27,80 \%$.

Tabel 4. Permeabilitas Air Murni Membran PEI (Variasi Temperatur Pengadukan)

\begin{tabular}{|c|c|c|c|}
\hline No & $\begin{array}{c}\text { Komposisi } \\
\text { Membran } \\
\left(\mathrm{PEl} / \mathrm{NMP} / \mathrm{NH}_{4} \mathrm{Cl}\right) \\
(\% \mathrm{~b} / \mathrm{b})\end{array}$ & $\begin{array}{c}\text { Temperatur } \\
\text { Pengaduka } \\
n\left({ }^{\circ} \mathrm{C}\right)\end{array}$ & $\begin{array}{c}\text { Fluks } \\
\left(\mathrm{L} / \mathrm{m}^{2} \text {.jam }\right)\end{array}$ \\
\hline 1 & \multirow{5}{*}{$12 / 84 / 4$} & 60 & 67.245 \\
\hline 2 & & 70 & 66.348 \\
\hline 3 & & 80 & 62.989 \\
\hline 4 & & 90 & 55.290 \\
\hline 5 & & 100 & 48.547 \\
\hline
\end{tabular}




\section{Ketahan termal membran PEI}

Hasil analisis termogravimetri menunjukkan bahwa material PEI telah terdekomposisi pada bagian tertentu sebagaimana yang tampak pada gambar 3 dan 4. Dekomposisi tersebut ditandai dengan terjadinya pengurangan massa membran PEI selama peningkatan temperatur uji. Reduksi massa yang pertama dan kedua telah terdeteksi pada rentang $100-200{ }^{\circ} \mathrm{C}$ yang berkaitan dengan pelepasan molekul air dalam bentuk uap dan pada rentang 220$260{ }^{\circ} \mathrm{C}$ untuk pelepasan NMP yang teradsorbsi pada permukaan membran PEI. Peristiwa reduksi massa yang ketiga terjadi pada rentang temperatur $500 \stackrel{\circ}{\circ}$, yang disebabkan oleh dekomposisi PEI. Data ini mengindikasikan kestabilan termal membran PEI yang lebih tinggi dibandingkan dengan membran komersial lainnya, seperti PSf dan PVDF. Sebagai tambahan, tidak terdeteksi adanya pengaruh signifikan komposisi larutan cetak dan temperatur pengadukan terhadap ketahanan termal membran PEI. Pada gambar 3 dan 4 tampak gambaran detail mengenai trend/pola penurunan massa pada membran PEI seiring dengan peningkatan temperatur uji.

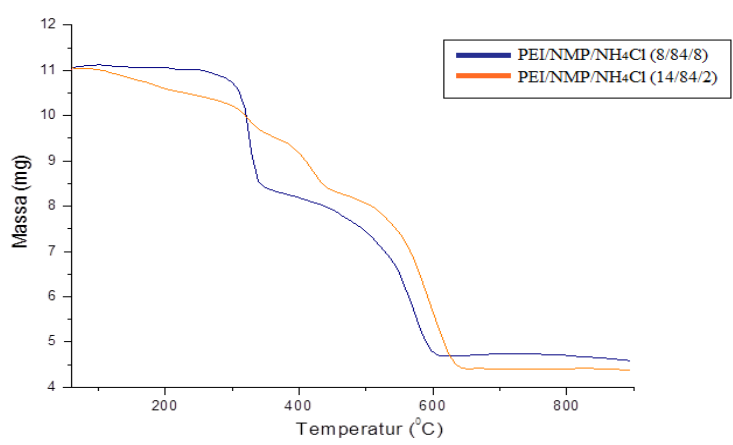

Gbr 3. Termogram membran PEI dengan variasi komposisi larutan cetak

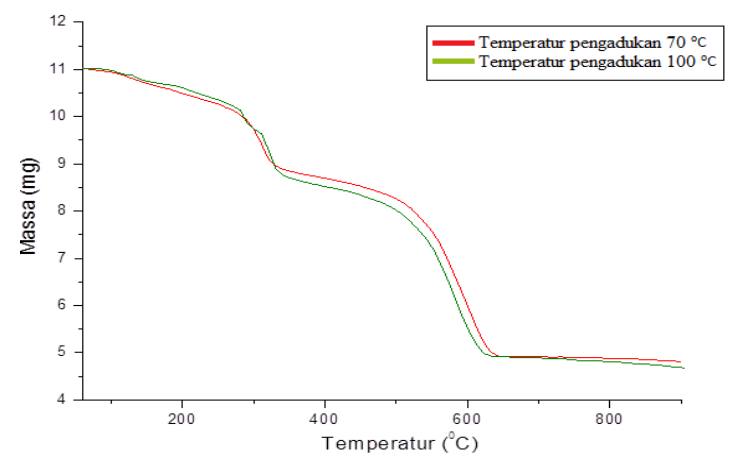

Gbr 4. Termogram membran PEI dengan variasi temperature pengadukan

\section{KESIMPULAN}

Hasil menunjukkan bahwa komposisi larutan cetak dan temperatur pengadukan memiliki pengaruh terhadap karakteristik fisik, mekanik dan permeabilitas air murni membran PEI. Pengaruh ini meliputi peningkatan kadar polimer PEI dalam larutan cetak dan temperatur pengadukan yang telah menciptakan membran PEI dengan porositas yang lebih tinggi dengan ukuran pori yang lebih kecil. Hasil optimasi komposisi larutan cetak dan temperatur pengadukan juga menunjukkan pengaruh keduanya terhadap peningkatan kemampuan membran dalam mempertahankan ukuran pori (modulus Young) ketika mendapatkan tekanan eksternal.

Berkebalikan dengan hasil tersebut, peningkatan kadar polimer PEI dan temperatur pengadukan telah mengasilkan penurunan permeabilitas air murni membran yang bersangkutan. Membran PEI dengan porositas tinggi, ukuran pori kecil dan nilai modulus Young terbaik didapatkan dari proses preparasi membran dengan meggunakan komposisi larutan cetak PEl/NMP/NH$/ \mathrm{NCl}_{4}$ (\%b/b) 14/84/2 dan temperatur pengadukan $100 \stackrel{\circ}{\circ}$. 
Sebaliknya, membran PEI dengan nilai permeabilitas air murni yang terbaik didapatkan dari proses preparasi membran dengan menggunakan komposisi larutan cetak $\mathrm{PEI} / \mathrm{NMP} / \mathrm{NH}_{4} \mathrm{Cl}(\% \mathrm{~b} / \mathrm{b})$ 8/84/8 dan temperatur pengadukan $60{ }^{\circ} \mathrm{C}$.

Membran PEI yang dihasilkan pada penelitian ini memiliki kekuatan mekanik pada rentang $1.124-1.898 \mathrm{~N} / \mathrm{m}^{2}$ dan permeabilitas air murni pada rentang 48.574 - 101.553 $\mathrm{L} / \mathrm{m}^{2}$.jam. Sebagai tambahan, membran PEI memiliki ketahanan termal hingga mencapai temperatur $500 \stackrel{\circ}{\mathrm{C}}$.

\section{UCAPAN TERIMA KASIH}

Ucapan terima kasih diberikan kepada Direktorat Riset dan Pengabdian kepada Masyarakat (DRPM) Kementrian Riset dan Teknologi Pendidikan Tinggi (Kemenristek Dikti) yang telah memberikan dukungan dana penelitian melalui skema Program Penelitian Unggulan Perguruan Tinggi tahun anggaran 2016.

\section{DAFTAR PUSTAKA}

[1] Elsevier, Comprehensive Membrane Science and Engineering. USA : Elsevier, 2010.

[2] N.A., Hashim, F. Liu, K. Li, "A simplified method for preparation of hydrophilic PVDF membranes from an amphiphilic graft copolymer.," Journal of Membrane Science, vol. 34, pp. 134-141, 2009.

[3] F. Liu, N.A., Hashim, Y. Liu, M.R.M. Abed, K. Li, "Progress in the production and modification of PVDF membranes," Journal of Membrane Science, vol. 375, pp. 1-27, 2011.

[4] A.A.S., Abadi, R.M.M. Behbahani, F. Seidi, M. Soroush, "Physical aging of polyetherimide membranes," Journal of Natural Gas Science and Engineering, vol. 27,pp. 651-660, 2015.

[5] Z.A. Tarsa, S.A.A. Hedayat, M.R. Sisakht, "Fabrication and characterization of polyetherimide hollow fiber membrane contactor for carbon dioxide stripping from monoethanolamine solution, " Journal of Membrane Science and Research, vol. 1, pp. 118-123, 2015.

[6] R.W., Baker, Membran Technology and Applications $2^{\text {nd }}$ Edition. England : John Wiley \& Sons, Ltd., 2004.

[7] N.J. Kaleekkal, A. Thanigaivelan, D. Rana, D. Mohan, "Studies on carboxylated graphene oxide incorporated polyetherimide mixed matrix ultrafiltration membranes," Materials Chemistry and Physics, vol. 186, pp. 146-158, 2017.

[8] T.J. Ainscough, D.L. Oatley-Radcliffe, A.R. Barron, "Parametric optimization for the fabrication of polyetherimide-sPEEK asymmetric membranes on a non-woven support layer," Separation and Purification Technology, vol. 186, pp. 78-89, 2017.

[9] W.R. Bowen, S. Cheng, T. Doneva, D. Oatley, "Manufacture and characterization of polyetherimide/sulfonated poly(ether ether ketone) blend membranes, " J. Membr. Sci., vol. 250, pp. 1-10, 2005.

[10] M. Grasselli, N. Betz, "Making porous membranes by chemical etching of heavy-ion tracks in [beta]-PVDF films," Nuclear Instruments and Methods in Physics Research Section B: Beam Interactions with Materials and Atoms, vol. 236., pp. 501-507, 2005.

[11] M. Mulder, The Use of Membrane Process in Water Purification. Proceeding. Bandung, 1996.

[12] M.G. Buonomenna, P. Macchi, M. Davoli, E. Drioli, "Poly(vinylidene fluoride) membranes by phase inversion: the role the casting and coagulation conditions play in their morphology, crystalline structure and properties," Eur. Polym. J., vol. 43, pp. 1557-1572, 2007.

[13] A.K. Hołda, B. Aernouts, W. Saeys, I.F.J. Vankelecom, "Study of polymer concentration and evaporation time as phase inversion parameters for polysulfone-based SRNF membranes," J. Memb. Sci. , vol. 442, pp. 196205, 2013.

[14] K. Hendrix, G. Koeckelberghs, I.F.J. Vankelecom, "Study of phase inversion parameters for PEEK-based nanofiltration membranes," J. Memb. Sci., vol. 452, pp. 241-252, 2014. 